\title{
Development of Groundwater Sustainability Framework with Hydrological Parameters of C52 Tertiary Catchment of the Upper Orange River System of South Africa
}

\author{
Saheed Adeyinka Oke and Rebecca Alowo \\ Department of Civil Engineering, Central University of Technology, Bloemfontein, \\ Free State Province, South Africa, okesaheed@gmail.com; soke@cut.ac.za.
}

\begin{abstract}
This study discusses the development of a framework that models groundwater sustainability for a catchment. Groundwater sustainability is important due to negative impact of increasing urbanization and climate change on groundwater resources in catchments. The hydrological parameters with human induced factors of the tertiary C52 catchment situated in the Upper Orange River was used as working tool in the design of conceptual framework. The framework also captured the major interactions and relationships within the C52 hydrological system which were reported as weighting and scoring systems in an indices format. A number of factors are reviewed as part of the methodology these were human (rights/equity), climate and aquifer and socio economic factors. As with sustainability analysis, the human factors capture the impact of anthropogenic activities on groundwater. The human factors are considered in a number of parameters as with regard to the C52 catchment, the pump rate per year, the number of permits issued per year, number of boreholes and the duration of the permits. The climate factors mainly considered the elements of: evapotranspiration, climatic zones, precipitation, sunshine, topography and slope. Yields, recharge, storativity, lithology/rock types and aquifer types were modelled as part of the aquifer system while the land and socio-economic factors were population, per capita use, tariffs and general water use category. From a simulation, view point these factors represent the interdependent processes in the $\mathrm{C} 52$ catchment. They further facilitate their rankings and analysis. The outcome of this research has been a framework for mapping sustainability a useful decision making support system for groundwater management.
\end{abstract}

Key words: Modder River catchment, groundwater sustainability, sustainability indices, Upper Orange River, C52 catchment, general water

\section{INTRODUCTION}

A model is defined as "abstracts designed and created as a result of operational logic, physical formulae and intuitive experimental decision making" (Linard et al., 2009). Hydrological models are simplified, representations of the hydrologic cycle. Hydrological modelling is important in understanding hydrologic processes at catchment level (Dingman, 2015). Groundwater models are part of hydrological models. Research alludes groundwater modelling to assist in aquifer property estimation, predictions and resource management (Devia et al., 2015). Models should be tenable, scientifically sound and robust if they are to be used for research or regulation purposes (Chow et al., 1988; Teng et al., 2017).

A physically based model represents the product of factorization of hydrological processes. These hydrological processes are in the form of nonlinear partial differential equations that cannot be solved analytically (Beven et al., 1980). Few examples of physically based hydrological models available are: ACRU, AnnAGNPS, ANSWERS-2000, HSPF, MIKE SHE, SWAT and MODFLOW (Brunner and Simmons, 2012). Like all models, numeric models present challenges and short comings. These gaps are because of assumptions made when developing the models, the errors from measured hydrogeological data and boundary controls (Buck, 2016). The result of a model has a number of errors which are both known and unknown. These could be:

- The method used to solve the derived differential equations

- The inaccurate values of the catchment/system (conditions, properties and stresses)

- The level of correctness or exactness between the real system and the model (Chemical and physical processes of the model) (Mehl and Hill, 2004)

Corresponding Author: Saheed Adeyinka Oke, Department of Civil Engineering, Central University of Technology,

Bloemfontein, Free State Province, South Africa; okesaheed@gmail.com 
Groundwater is one of the most abstracted global raw materials and natural resources (UNESCO, 2006; Molz III, 2017). There is a balance between space and time in the natural occurrence of groundwater. It is also increasingly found that groundwater development in most places happens without the understanding of this balance. How groundwater is recharged and its impact on the environment is complex and not completely understood. As a result, groundwater is excessively pumped leading to depletion. Decline in water levels in aquifers caused by depletion and therefore, decrease in the yield of water wells, salinity intrusion and land subsidence in coastal aquifers. This has raised uneasiness across the globe (Reddy, 2011; Giupponi, 2017).

The concept of groundwater sustainability considers a long to medium approach to management of groundwater. There are many reasons for this: the uniqueness of groundwater to function as a partial renewable resources (through hydrological cycle) and as non-renewable (not all groundwater withdrawal are replenished) resource and when recharge from rainfall is not commiserate to groundwater abstraction rates (Asano, 1985). Therefore, groundwater sustainability becomes of great importance. Roberts in his analysis of water use in South Africa, states the linkages between economic gains and population growth given their influence on each other. This suggests human and climatic impact determines to a larger degree the sustainability of South African groundwater resources. South Africa is known to be water stressed country due to the fact that it receives an average rainfall of $450 \mathrm{~mm} /$ year (NPC., 2013) in most parts which fall short of the world average rainfall of 860 $\mathrm{mm} /$ year (NPC., 2013). South Africa location in the semiarid region of the world compounds its water scarcity problem. Therefore, there is need for sustainable use of South African water resources.

The negative trends of climate change and its threats are affecting groundwater in the Upper Orange River catchment (DWS., 2016). The main undesirable effect has been higher population growth rates in the cities and unchecked urbanization. It resulted from the fact the Upper Orange areas has had extend periods of decreased rainfall and drought. This has set a chain reaction of over abstraction as demand for water increases. Over pumping of aquifers becomes the norm as recharge is low to both surface and groundwater (NPC., 2013). These problems are compounded with the facts that the Upper Orange catchment is situated in arid and semi-arid areas of South Africa with farmers and communities in the area, having limited number of water provision points (Department of Water Affairs DWA, 2013). These has put undue pressure on aquifers and water catchments such as the C52 Modder River catchment (a sub-catchment of the Upper Orange River) as more wells and boreholes have been drilled to access groundwater continuously. Therefore, there is a need to develop groundwater sustainability models for groundwater monitoring that can be used to make an informed decision for better groundwater management.

Groundwater and climatic system of the Upper Orange River basin: The Orange River basin is situated in South Africa but its stretches also covers Botswana, Namibia and Lesotho. The Orange River basin is the largest of all the river basins in Southern Africa of which almost $600,000 \mathrm{~km}^{2}$ falls within South Africa (Department of Water Affairs DWA, 2013). The C52 catchment is based mostly within the upper orange part of this river basin with a total area of $17,366 \mathrm{~km}^{2}$ and falls largely within South Africa (DWS., 2016). The C52 catchment is located to the East of Bloemfontein city in the province of the Free State in South Africa. The distribution of boreholes in the C52 catchment used for this study is shown in Fig. 1. The major river flowing through the catchment is the Modder River which flows into the main Orange River.

The C52 catchment is located within the Karoo basin of South Africa. Groundwater in the Karoo is found in contact zones of dykes and sills, intrusive rocks and weathered rock sections (Usher et al., 2005). The major rock types underlying the C52 catchment are dolerite, mudstone, sandstone and shale. The geology comprises of the Ecca group and Beaufort Group (Chevallier et al., 2001). Groundwater yield of the Karoo is generally limited $(0.31 / \mathrm{sec})$, except in some areas where large volumes are pumped out to supply towns and mines (Chevallier et al., 2001). According to the national Department of Water and Sanitation (DWS., 2016) the variation of rainfall is 500-450 $\mathrm{mm} /$ year. The vegetation that covers the C52 catchment is savannah grassland. This is generally termed as the Karro belt which extends from East to West (Department of Water Affairs, 2013). The topography consist of hilly terrains of the Maluti Mountains of Lesotho into wide plains of shrubs (Department of Water Affairs, 2013).

The ability to supply water directly from groundwater aquifers to the farmers and other water users depends fundamentally on the availability of rainfall which is a major source of groundwater recharge in the area (DWS., 2016). Other hydrological parameters that affect groundwater sustainability in the catchment are the geology, soil types, climatic condition and slopes. 


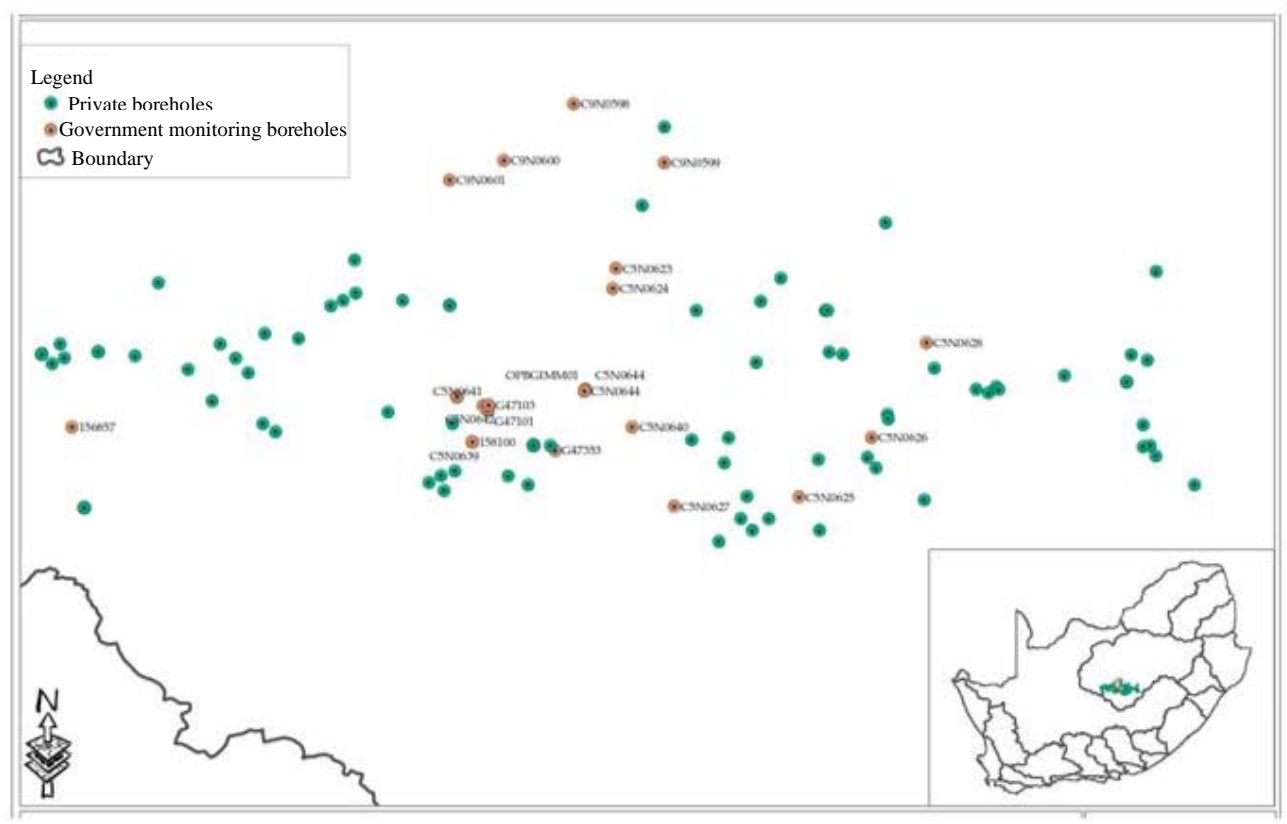

Fig. 1: Location of boreholes in C52 tertiary catchment

\section{MATERIALS AND METHODS}

Concept of the modelling framework: The conceptual framework is based on the physical processes governing hydrological cycles in relation to groundwater sustainability in the Upper Orange River catchment. The processes and their interactions are grouped as factors and include climatic, socio-economic and land use, aquifer sustainability, right and equity of resources Fig. 2. The interactions are further grouped into four categories as follows:

- Climate-surface water-groundwater interactions

- Land use-surface water-groundwater interactions

- Climate-land use-groundwater interactions

- Climate-groundwater interactions

Climate and rainfall forms most of groundwater recharge. Precipitation that infiltrates and percolates the Earth's surface has three paths:

- Capillary action forcing water into the vadose zone

- High temperatures causing evapotranspiration

- Infiltration and percolation contributing to the water table (Ponce, 2006)

Fundamental difference between infiltration and percolation is that infiltration water is the source that supply to springs, rivers and streams. While deep groundwater flow or groundwater run out flows deeper in the Earth without intercepting the land surface.

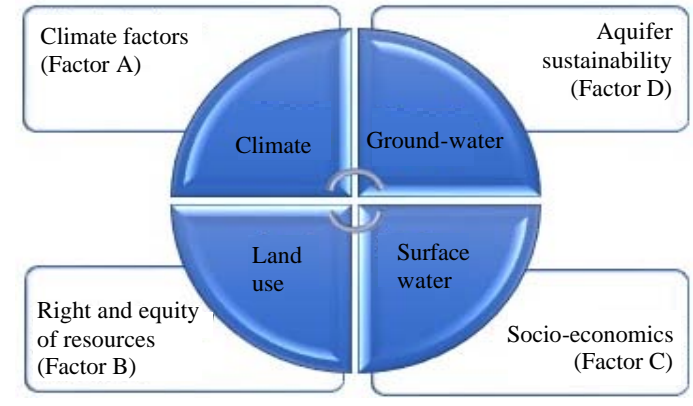

Fig. 2: Interactions of the hydrological modelling framework

Groundwater recharge is affected by human activity. This activity may be as a result of pumping of water from an aquifer for socio economic activity such as farming (Asano, 1985). In this process, groundwater flow direction changes towards areas exerting the highest pressure. Increasing groundwater can also be stored through artificial recharge (Asano, 1985).

The amount of groundwater recharge and discharge is the motivation for sustainability model developments. Sustainability is a link between the processes and their interactions because any amount of groundwater extracted through well pumping (as a result of land use, ownership and right) successfully alter water movement in the hydrological cycle.

The sustainability framework: The framework was based on the observed indicators that influence groundwater. 
These indicators were grouped into the following factors: factor A (climate scenario), factor B (right and equity of resources), factor $\mathrm{C}$ (socio-economic activities and land use) and factor D (aquifer sustainability).

Factor $\mathrm{A}$ is the climatic conditions dominant in the C52 catchment area. This includes the rainfall that the Upper Orange River receives which represents the potential groundwater recharge from infiltration and subsequent percolation into the aquifer. Evapotranspiration in the catchment ranges from 400 and $500 \mathrm{~mm}$ (DWS., 2016). This is higher than the average rainfall of $400 \mathrm{~mm} /$ year for this region (DWS., 2016). The sunshine range of $15-45^{\circ} \mathrm{C}$ leads to the arid and semi-arid climatic zones present in the area. Other indicators considered in the climatic conditions are the slopes and climatic zones. The data used in modelling the factor $\mathrm{A}$ framework were sourced from the South African weather service.

Factor B considers the rights and equity of the water usersrelating to the groundwater resources of the catchment. These are made up of the duration or length of the borehole permit issued, the number of borehole permits issued per year, pump rate per year and the number of actual boreholes drilled and currently in the Upper Orange River. These indicators are monitored and available at the Department of Water and Sanitation (DWS). Factor B, therefore, represents the groundwater abstraction rate in the aquifer. In addition to the DWS, regulating the right of the water users to exploit the groundwater resources, they also issue permits and keep records of the groundwater yields.

Factor $\mathrm{C}$ is the socio-economic activities of the catchment as related to their impact on the groundwater resources. The indicator considered in this factor consists of the per capita use of the catchment where boreholes are located, population of the C52 catchment, tariffs paid based on the use the economic activities of the users and the purpose of the groundwater use (mining, agriculture, and domestic and energy development). Factor $\mathrm{C}$ represents the potential use of the water, the economic growth that relies on the groundwater abstracted and the activities that impact the groundwater abstraction. Generally, these indicators represent the main activities that influence the groundwater sustainability of the C52 catchment. These indicators are monitored and available at the DWS.

Factor D explores the aquifer system sustainability. Key indicators of importance which affect aquifer system sustainability are the rock type hosting the groundwater and type of aquifer system in place (confined, unconfined, semi-confined and fractured). Non-fractured basement rock will have little sustainability while the sustainability of fractured basement rock will depend on the distribution, range of width and frequency of fracture variation (joints, faults, lineaments and cavities). The rest of the indicators that also affect the sustainability of the aquifer system are: aquifer yields in liter per second, recharge in millimeter per year, aquifer storage (measured as storage gross volume in cubic meter per year) and water quality. Factor D, therefore, represents the groundwater interactions and processes in the aquifer. It is important to explore the aquifer system sustainability in the catchment separately because of the possibility of some aquifers sustaining itself irrespective of the socio-economic activities that the aquifer supports. Aquifers are recharged through several processes including rainfall, infiltration and percolation, through recharge mechanisms and other hydrological processes that affect groundwater sustainability. The higher the population number in a catchment, the higher the socioeconomic activities (agriculture, mining, industrial and domestic), the higher their demands, the more permits issued and this put the aquifers in vulnerable and less sustainable conditions.

\section{RESULTS AND DISCUSSION}

Sustainability index: The sustainability index acronym is derived from the initial letters of the factors used in the formula: A: B: C: D. The sustainability was computed by combining the factors of climatic conditions, rights and equity as related to the groundwater resources, socio-economic activities and the aquifer system sustainability. This is proposed in the following Eq. 1:

$$
\mathrm{S}=\sum \mathrm{A}+\mathrm{B}+\mathrm{C}+\mathrm{D}
$$

Where:

$\begin{aligned} \mathrm{A} & =\text { Climatic condition score } \\ \mathrm{B} & =\text { Rights and equity score } \\ \mathrm{C} & =\text { Socio-economic score } \\ \mathrm{D} & =\text { Aquifer system score } \\ \mathrm{S} & =\text { Sustainability } \\ \mathrm{A} \text { and D }= & \text { A weighting of } 30 \text { each while } \mathrm{B} \text { and C had a } \\ & \text { weighting of } 20 \text { each }\end{aligned}$

The final sustainability factors were added up because they all impact groundwater sustainability. Factor $\mathrm{A}$ and D (climatic conditions and aquifer system) are complex in the natural context and therefore, responsible for percolation and infiltration. Factor A carried an equal weight with factor $D$ because the sustainability methods assume rainfall as the principle climatic condition and initiator of the infiltration and percolation which contributes to recharge and later becomes groundwater. The implication is that if rainfall or another recharge mode is absent there is no formation of groundwater. The impact on groundwater sustainability by factor B and C may be higher on the analysis as human activity will deplete whatever groundwater is available and not replenished. For this reason, the weights of the two factors were the same (Fig. 3). 


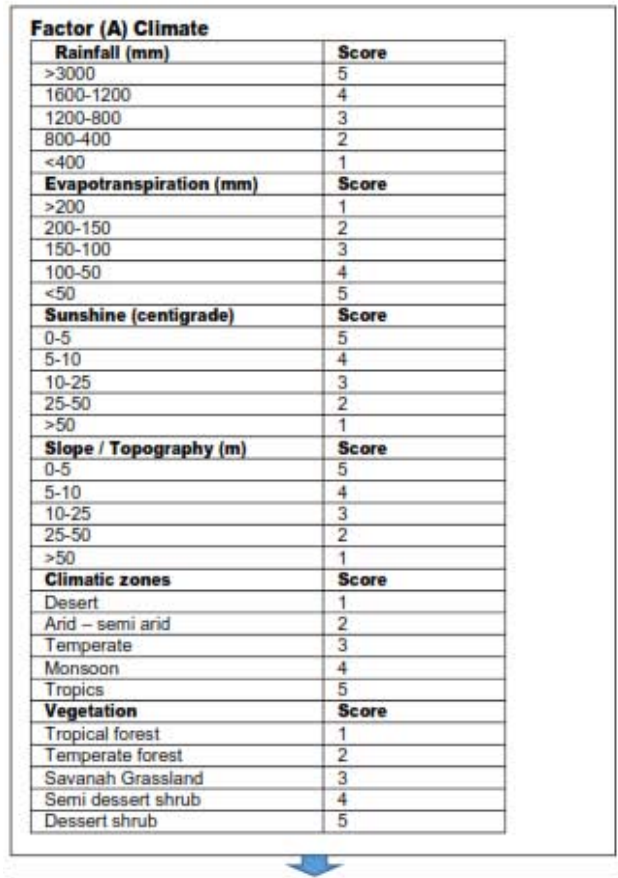

\begin{tabular}{|c|c|c|}
\hline Sustainabillty ( & ¿A.B.C.D & \\
\hline $\begin{array}{l}\text { Sustainability } \\
\text { index }\end{array}$ & $\begin{array}{l}\text { Sustainability } \\
\text { class }\end{array}$ & \multirow{6}{*}{ 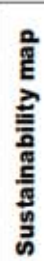 } \\
\hline $19-35$ & Very low & \\
\hline $35-51$ & Low & \\
\hline $51-67$ & Moderate & \\
\hline $67-83$ & High & \\
\hline $83-100$ & Very high & \\
\hline
\end{tabular}

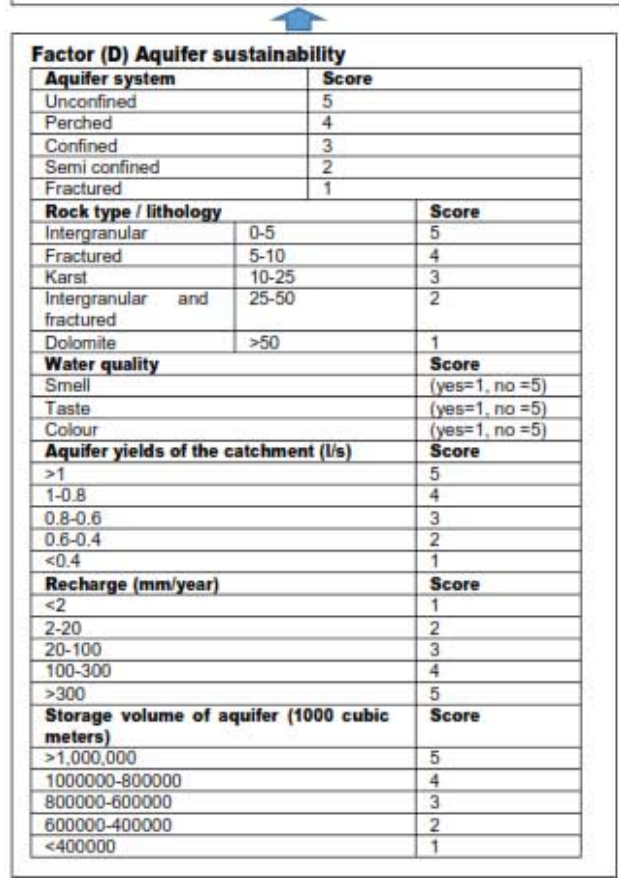

Factor (B) Rights/equity verse resources
\begin{tabular}{|l|l|}
\hline $\begin{array}{l}\text { Number of permits issued in the } \\
\text { catchment per year }\end{array}$ & Score \\
\hline$<1$ & 5 \\
\hline $1-2$ & 4 \\
\hline $2-3$ & 3 \\
\hline $3-4$ & 2 \\
\hline$>5$ & 1 \\
\hline Length or duration of permit years & Score \\
\hline $0-5$ & 5 \\
\hline $5-10$ & 4 \\
\hline $10-15$ & 3 \\
\hline $15-20$ & 2 \\
\hline 20 & 1 \\
\hline $\begin{array}{l}\text { Number of boreholes in the sub } \\
\text { catchment }\end{array}$ & Score \\
\hline $0-25$ & 5 \\
\hline $25-50$ & 4 \\
\hline $50-75$ & 3 \\
\hline $75-100$ & 2 \\
\hline$>100$ & 1 \\
\hline $\begin{array}{l}\text { Pump rate }(1000 \text { cubic meters per } \\
\text { year) }\end{array}$ & Score \\
\hline$>1,000,000$ & 1 \\
\hline $1000000-800000$ & 2 \\
\hline $800000-600000$ & 3 \\
\hline $600000-400000$ & 4 \\
\hline$<400000$ & 5 \\
\hline & \\
\hline
\end{tabular}

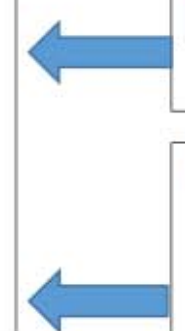

$<400000$

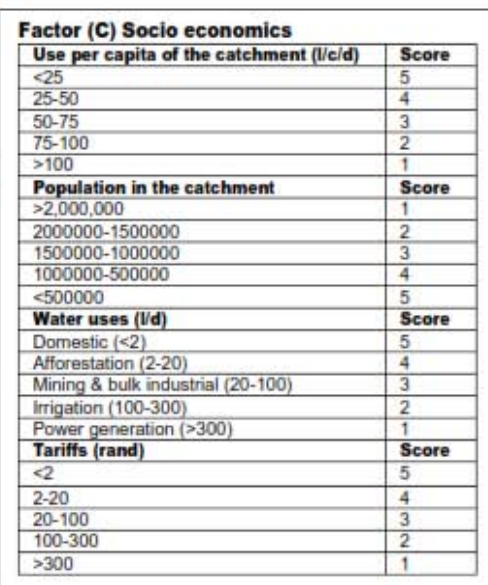

Fig. 3: Idealized illustration of the sustainability model 
The sustainability index was grouped into five classes. The classes and sustainability values are presented in Fig. 3. The final groundwater sustainability index class score of 19-35 means a very low sustainability, 35-51 means low sustainability, 51-67 means moderate sustainability, 67-83 means a high sustainability and 83-100 means a very high sustainability. The rankings were based on a scoring system from the highest score of 100 which implies a highly sustainable system to the lowest score of 19 which suggests the least sustainable. A rating of 1 was assigned to severe impact and a rating of 5 to least impact on the groundwater sustainability status.

The high and very high sustainability classes correspond to areas with favorable climatic conditions, favorable groundwater interaction and processes (fast rate aquifer system, especially, recharge). The high classes also have less abstraction and socio-economic activity. The moderate to low classes suggest areas to the opposite of the previous scenario too much abstraction activity an unfavorable climatic condition and slow or to little groundwater processes and interactions (high or steep slopes and low rainfall).

\section{CONCLUSION}

The developed methodological framework for calculating groundwater sustainability presented in this study uses concept guiding methodology of reporting sustainability generally. The sustainability indices makes use of subjective reporting techniques of weight and scoring systems of physical variables. Hydrological and human induced parameters are grouped into four factors of aquifer systems, climatic conditions prevalent in the area, land use and social-economic activities and right to resources. The sustainability parameters for evaluation are easy to collate and presented in an easy way for calculation. The framework has been designed for areas such as the C52 Upper Orange River basin and other catchments with similar challenges, particularly those in South Africa but also globally. The sustainability class is similar to that of other assessment methods and the sustainability classes ranged from very low to very high groundwater sustainability.

\section{ACKNOWLEDGEMENT}

The second researcher has received research funding from the Central University of Technology, Free State for her doctoral studies.

\section{REFERENCES}

Asano, T., 1985. Artificial Recharge of Groundwater. 1st Edn., Butterworth Publisher, Boston, Massachusetts, USA., ISBN:9780250405497, Pages: 767.

Beven, K., R. Warren and J. Zaoui, 1980. SHE: Towards a methodology for physically-based distributed forecasting in hydrology. IAHS Publ., 129: 133-137.

Brunner, P. and C.T. Simmons, 2012. HydroGeoSphere: A fully integrated, physically based hydrological model. Groundwater, 50: 170-176.

Buck, I., 2016. Managing to end groundwater overdraft in Californias Central Valley with climate change. Master Thesis, University of California, Davis, California, USA.

Chevallier, L.P., M.L. Goedhart and A.C. Woodford, 2001. Influence of Dolerite Sill and Ring Complexes on the Occurrence of Groundwater in Karoo Fractured Aquifers: A Morpho-Tectonic Approach: Report to the Water Research Commission. Water Research Commission, Lynnwood Manor, Pretoria, South Africa, ISBN:9781868457083, Pages: 146.

Chow, V.T., D.R. Maidment and L.W. Mays, 1988. Applied Hydrology. 2nd Edn., McGraw-Hill, New York, USA., ISBN:9780071001748, Pages: 572.

DWS., 2016. National groundwater resource assessment phase II. Department of Water and Sanitation, Pretoria, South Africa.

Department of Water Affairs (DWA), 2013. National Water Resource Strategy: Water for an Equitable and Substainable Future. 2nd Edn., Department of Water Affairs, Pretoria, South Africa, Pages: 201.

Devia, G.K., B.P. Ganasri and G.S. Dwarakish, 2015. A review on hydrological models. Aquatic Procedia, 4: 1001-1007.

Dingman, S.L., 2015. Physical Hydrology. 3rd Edn., Waveland Press, Long Grove, Illinois, USA., ISBN:978-1-4786-1118-9, Pages: 643.

Giupponi, C., 2017. Integrated groundwater management: Concepts, approaches and challenges. Environ. Modell. Software, 93: 161-162.

Linard, J.I., D.M. Wolock, R.M.T. Webb and M.E. Wieczorek, 2009. Identifying hydrologic processes in agricultural watersheds using precipitation-runoff models. MSc Thesis, US Department of the Interior, Washington, DC., USA.

Mehl, S. and M.C. Hill, 2004. Three-dimensional local grid refinement for block-centered finite-difference groundwater models using iteratively coupled shared nodes: A new method of interpolation and analysis of errors. Adv. Water Resour., 27: 899-912. 
Molz III, F.J., 2017. The development of groundwater modeling: The end of an era. Groundwater, 55: $1-1$.

NPC., 2013. National development plan vision 2030. National Planning Commission, Pretoria, South Africa.

Ponce, V.M., 2006. Groundwater utilization and sustainability. MSc Thesis, San Diego State University, San Diego, California, USA.

Reddy, P.J.R., 2011. A Textbook of Hydrology. 3rd Edn., Laxmi Publications, New Delhi, India, ISBN:9789380856049, Pages: 523.
Teng, J., A.J. Jakeman, J. Vaze, B.F. Croke and D. Dutta et al., 2017. Flood inundation modelling: A review of methods, recent advances and uncertainty analysis. Environ. Modell. Software, 90: 201-216.

UNESCO., 2006. Non-renewable Groundwater Resources: A Guidebook on Socially-sustainable Management for Water-policy Makers. UNESCO, Paris, France, Pages: 103.

Usher, B.H., J.A. Pretorius and G.J. Van Tonder, 2005. Management of a Karoo fractured-rock aquifer system-kalkveld Water User Association (WUA). Water SA., 32: 9-19. 